\title{
Evaluating the Effect of Peer-Assisted Education on the Functioning in Family Caregivers of Patients with Schizophrenia: A Clinical Trial Study
}

\author{
Nahid Rajai', Behnaz Lami ${ }^{2}$, Amir Hosein Pishgooie ${ }^{3}$, Hengameh Habibi ${ }^{4}$ Fatemeh Alavizerang ${ }^{5, *}$ \\ 'Department of Mother and Infant, School of Nursing, Aja University of Medical Sciences, Tehran, Iran \\ ${ }^{2}$ Department of Psychiatric Nursing, Baghiyyatollah Al-Azam Hospital, Tehran, Iran \\ ${ }^{3}$ Department of Intensive Care, School of Nursing, Aja University of Medical Sciences, Tehran, Iran \\ ${ }^{4}$ Department of Pediatric Nursing, School of Nursing, Aja University of Medical Sciences, Tehran, Iran \\ ${ }^{5}$ Department of Nursing, School of Nursing and Midwifery, Islamic Azad University of Medical Sciences, Varamin-Pishva Branch, Tehran, Iran
}

Background: High levels burden of long-term care of patients with schizophrenia can disrupt the functioning of family caregivers. This study evaluated a peer-assisted education method on family caregivers' functioning of patients with schizophrenia.

Methods: In this randomized controlled trial, 64 family caregivers of schizophrenia patients in military hospitals of Tehran, Iran, were selected and randomly allocated to intervention and control groups, in 2018-2019. The peer-assisted education was performed in the experimental group for six 1-hour sessions and the family functioning was measured in both groups by the Family Assessment Device Scale. The data were analyzed by SPSS software ver. 16.0 (SPSS Inc., Chicago, IL, USA) and group differences at a level of P-value $<0.05$ were considered as significant. Results: There was no significant differences between groups in the pre-intervention phase in all dimensions of family functioning $(\mathrm{P}>0.05)$. There were significant differences between intervention and control groups, in the post-intervention phase in mean problem-solving dimension ( 11.80 vs. $15.53, \mathrm{P}=0.012$ ) and in 2 weeks after intervention, in the dimensions of roles (21.71 vs. $23.43, \mathrm{P}=0.015$ ), affective involvement (19.03 vs. $21.59, \mathrm{P}=0.017$ ), behavior control ( 23.90 vs. $26.93, \mathrm{P}=0.045$ ), general functioning ( 27.15 vs. $31.40, \mathrm{P}=0.013$ ), and total family functioning (134.12 vs. 153.09, $\mathrm{P}=0.001)$.

Conclusion: The peer-assisted education significantly influenced the functioning of family caregivers of schizophrenic patients and can be recommended to improve the functioning of caregivers.

Keywords: Caregivers; Education; Family; Functioning; Peer; Schizophrenia

Received: April 27, 2020, Revised: June 24, 2020, Accepted: June 25, 2020

${ }^{*}$ Corresponding Author: Fatemeh Alavizerang https://orcid.org/0000-0003-3580-4087

Tel: +98-9123366365, Fax: +98-21-3672-4767, E-mail: f.alavizerang@iauvaramin.ac.ir 


\section{INTRODUCTION}

Schizophrenia appears to be one of the most important and debilitating mental disorders. Its prevalence in the world is 36.6 per 1,000 people. ${ }^{1)}$ The prevalence of psychotic diseases in Iran has been reported to be $0.89 \%$ and the prevalence of schizophrenia is $0.6 \%$ (about 450,000 affected people). ${ }^{2)}$

More than $50 \%$ of patients with psychosis are living with their family and burden of caring was borne by them, especially those in the early stage period. ${ }^{3,4)}$ The extensive cognitive-emotional and motor symptoms in schizophrenic patients cause special needs for their care. ${ }^{5)}$ For this reason, the tensions and stresses of family caregivers of schizophrenia patients are more than other psychiatric patients. ${ }^{6)}$ The common problems among the families of schizophrenic patients include the lack of information, stigma, family conflicts, and absence of social support, which, of course, have adverse effects on the physical and mental health of the families. ${ }^{7)}$ In this context, the results of research on 225 family caregivers of schizophrenic patients revealed that $41.8 \%$ of caregivers experienced "moderate to severe" and 27.1\% "severe" burden. ${ }^{8)}$

The main complication of burden is to disrupt the personal and social functioning of the patient and family members. ${ }^{2}$ Family functioning involves collaborative methods, approaches, and efforts used by the family to maintain its cohesion. ${ }^{9)}$ In fact, the presence of a chronic mental patient in the family has a profound effect on the family system and according to the World Health Organization, schizophrenia is one of the 10 diseases that lead to a lack of function in people. ${ }^{10,11)}$ Schizophrenia also affects the family functioning and leads to a conflict between family members and, thus, exacerbates the disease symptoms. ${ }^{12)}$ Based on McMaster model, family functioning consists of six dimensions, including problem-solving, communication, roles, affective responsiveness, affective involvement, and behavior control. ${ }^{13)}$ The schizophrenic patients' families have weaknesses in these dimensions and require to take measures to improve them. ${ }^{5,11)}$

The educational need is the most important care need of the caregivers. ${ }^{14)}$ For example, Nadem Buoeni et al. ${ }^{15)}$ showed a poor level of knowledge of caregivers of schizophrenia patients (10.66 \pm 2.66 out of a maximum mean of 20). Numerous studies have shown that teaching to the family caregivers of schizophrenic patients leads to reduce anxiety, depression, and recurrence of symptoms and enhanced functioning of the family and effectiveness of medications. ${ }^{2,9,16}$ Peer-assisted education is a less structured' training methods that emerged in the 1990s. The peer group consists of motivated individuals with similar life situations ${ }^{17,18)}$ who sharing their useful and productive experiences. ${ }^{19)}$ Peer-assisted education develops the people's knowledge, attitude, and skills. ${ }^{20)}$ The individuals in the peer groups can better communicate with their peers and encourage them to choose the right healthy behaviors since they share their weaknesses, strengths, and experiences with each other at the lowest cost. The positive impact of this educational method also was confirmed by several studies., ${ }^{9,16)}$

Given the severe shortage of nursing staff in Iranian military hospi- tals and the limited time to train the families, the peer-assisted education may help to resolve this problem. Also, family caregivers of schizophrenics have more problems in military families due to special living and working conditions. ${ }^{21)}$ Therefore, this study aimed to determine the effect of peer-assisted education on the functioning of family caregivers of patients with schizophrenia in military families.

\section{METHODS}

The present study was a randomize controlled trial, which was conducted on the family caregivers of schizophrenia patients admitted to psychiatric wards of two selected military hospitals in the city of Tehran in 2018-2019. The sample size was calculated in each group as 29.21 subjects with $95 \%$ confidence and type I error (0.05) and based on the mean and standard deviation functioning scores from the study of Navidian et al. ${ }^{2)}$ (Cohen's d=1.10, effect-size $\mathrm{r}=0.48$ ) according to the following formula. Thus, considering a $10 \%$ probability of sample loss in each group, 32 individuals were considered in each group (64 individuals in total).

$$
\begin{aligned}
& \mathrm{n}=\frac{\left(s_{1}^{2}+s_{2}^{2}\right)^{2}\left(z_{1-\frac{\alpha}{2}}+z_{1-\beta}\right)^{2}}{\left(\bar{x}_{1}-\bar{x}_{2}\right)^{2}} \\
& \mathrm{n}=\frac{\left(8.28^{2}+7.48^{2}\right)(17.84)^{2}}{(44.52-35.8)^{2}}=29.21
\end{aligned}
$$

The sampling was carried out, among the family caregivers (parents, children, and spouse) of patients with schizophrenia referred to psychiatric wards of the mentioned hospitals. The researcher screened family caregivers for eligibility base on the inclusion criteria and finally 64 eligible caregivers recruited to the study. The inclusion criteria were as follows: a minimum age of 18 years and a maximum age of 60 years, having literacy to write and read, co-living with a schizophrenic patient, not having a known mental illness, willingness to participate in the study, having a history of hospitalization of the schizophrenic patient, not having hearing and vision impairments, not history of drug use, and not experience of crises such as divorce and the death of the loved ones in the last 6 months. The exclusion criteria also included the caregiver diagnosed with a mental illness during the study period and being absent for more than two sessions of the training sessions.

The family caregivers were divided into two groups of the peer-assisted education group (intervention group) or the control group with method of simple random allocation using lottery. In total, 64 subjects were included in the study, and finally, the data of the 64 subjects were analyzed and no loss occurred in the samples (Figure 1). In this study, group assignment status was blinded to the data analyzers until the conclusion of the study.

Four family caregivers of schizophrenia patients were selected as the training peers who had a good speaking ability, successful experiences of care of schizophrenia patient for at least 2 years and were also eager to train others. During three 1-hour training sessions, the researcher trained the peers on the previously prepared training content. At the end of the third session, the peers were evaluated by a research- 


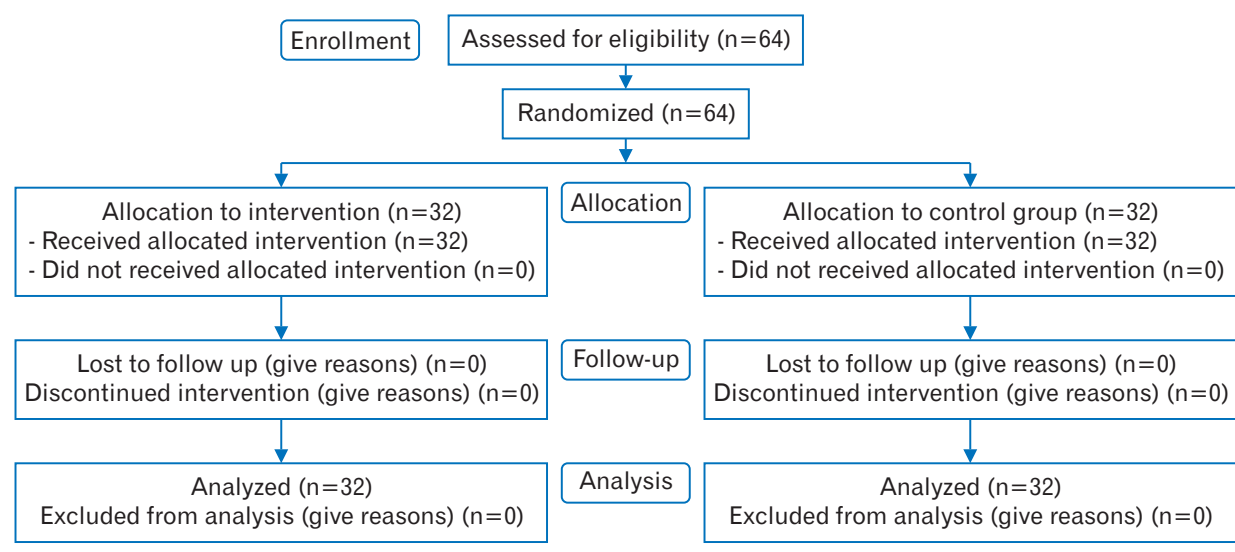

Figure 1. The CONSORT (Consolidated Standards of Reporting Trials) flow diagram of study for family caregivers of intervention and control groups.

Table 1. The educational content provided to the intervention group

\begin{tabular}{|c|c|}
\hline Sessions & Educational content \\
\hline First session & $\begin{array}{l}\text { Familiarity with the goals of the educational sessions, the role of the family in developing and maintaining the health of family members, introducing } \\
\text { caregivers to each other, and sharing the experiences on the disease symptoms and problems. }\end{array}$ \\
\hline Second session & Familiarity with schizophrenia, its care measures, the importance of drug treatment and its role in the prevention of the disease recurrence. \\
\hline Third session & $\begin{array}{l}\text { How to communicate with a psychiatric patient, how to care for and how to deal with the disease symptoms and signs, especially hallucinations, } \\
\text { delusions, aggression, and aggressive and invasive behaviors in patients, securing the patient's living environment, preventing aggressive, suicidal } \\
\text { situations and, in the case of occurring such events, how to refer them to the relevant health centers and other supportive settings. }\end{array}$ \\
\hline Fourth session & $\begin{array}{l}\text { Familiarity with the concept of stigma, training of methods of de-stigmatization, changing negative attitudes, beliefs, and thoughts of caregivers, and } \\
\text { strategies and solutions to reduce the caregivers' psychological burden. }\end{array}$ \\
\hline Fifth session & $\begin{array}{l}\text { Familiarity with non-pharmacological treatments such as exercise, proper relaxation method, its nature and importance in reducing anxiety, music } \\
\text { therapy, and a variety of traditional medicine therapies, teaching spiritual health promotion, how to fill the patient's leisure time, expressing problems } \\
\text { and feelings of the caregivers concerning the mentally ill patient. }\end{array}$ \\
\hline Sixth session & $\begin{array}{l}\text { Training of enhancing adaptive and communication skills and crisis management, teaching problem-solving skills and decision-making skills, teaching } \\
\text { methods for controlling the patient's behavior and life skills training, training effective methods to deal with negative emotions such as guilt, anger, } \\
\text { despair, and disappointment. }\end{array}$ \\
\hline
\end{tabular}

er-made checklist and the person who got the whole checklist score was selected as the training peer person.

In order to achieve a comprehensive educational content, the content was provided under the supervision of a psychiatrist, a clinical psychologist, and the researcher (psychiatric nurse) to enhance the family functioning of the family caregivers of schizophrenic patients. It was then approved by three faculty members of the Army University of Medical Sciences. Content of the training sessions are shown in Table 1.

In the experimental group, training sessions were organized in the hospital in coordination with the educational supervisor of hospital. The training sessions lasted for 3 weeks and two sessions per week (six 1-hour sessions in total). The samples were divided into two groups of 16 and the classes were held separately to better control the class conditions. The researcher taught the prepared content for 30 minutes in each session. The teaching method was giving a lecture using PowerPoint (Microsoft Corp., Redmond, WA, USA). The peer individual was then asked to express his experiences in the area of educational matters for 15 minutes. The last 15 minutes were also devoted to asking and answering questions from the participants and outlining their views to resolve the relevant problems.

The designed questionnaires were filled out by the samples before the beginning of the training sessions, at the end of the last session, and 2 weeks after the sessions to collect the data. No specific intervention was made in the control group and the control group data were also collected in three stages simultaneously with the intervention group. The control group was also provided with an educational content pamphlet at the end of the study to observe ethical aspects. Some gifts were presented to both intervention and control groups at the end of the training sessions.

Data collection tools included two questionnaires of demographic characteristics (included age, gender, marital status, education, frequency of hospitalization, and length of stay) and Family Assessment Device (FAD) questionnaire. The FAD questionnaire was developed by Epstein et al. ${ }^{13)}$ in 1983 . This tool was designed to assess family functioning, named as the McMaster Model of Family Functioning. The family measurement method in this model is problem-oriented. It has 60 questions and seven dimensions; it measures six family dimensions and one dimension of general family functioning as follows: problem solving (the family's ability to solve problems as well as the steps to do so), communication (effective, extensive, clear, and direct exchange of information in the family and refers to the efficiency of the family's approach to distribute and perform tasks), roles (tasks include affairs regarding providing resources "food, clothing, housing", nurturing and 
supporting, developing life skills and maintaining and managing a family system "e.g., housekeeping, life affairs, bills, health issues, and decision-making power"), affective responsiveness (the family members' solutions to show an appropriate emotional response, whether positive emotions "pleasure, love, attention, kindness, affection" or negative emotions "sadness, depression, anger, and fear"), affective involvement (the quality of interest, attention, and investment of family members concerning each other), and behavior control (behavioral standards and freedoms). Each question relates to one of these dimensions and describes the healthy and unhealthy functioning of the family. The subject can choose one of the following options for each question: strongly agree (score of 1 ), agree (score of 2), disagree (score of 3), and strongly disagree (score of 4 ). Therefore, the score of each scale is between 1 (healthy) and 4 (unhealthy). The questions that are the content of an unhealthy functioning description will be given a reverse score. In this instrument, a high score indicates the family ineffectiveness and a low score indicates family efficiency. If $40 \%$ of items of a scale are not completed, the scale score will not be calculated. ${ }^{13)}$

In a study, Yoosefi ${ }^{22)}$ mentioned the internal reliability (Cronbach's $\alpha$ ) of each of the FAD dimensions as follows: problem solving (0.86), communication (0.87), roles (0.87), affective responsiveness $(0.81)$, affective involvement (0.89), behavior control (0.87), and general functioning (0.82). This questionnaire has good validity with the power to distinguish clinical and non-clinical family members. ${ }^{22}$

In line with ethical considerations, this research was approved by the Ethics Committee of Army University of Medical Sciences under code IR.AJAUMS.REC.1397.049 and registered in the Iranian Clinical Trials (IRCT) System under the code IRCT 2018122180420040N1. The data were collected after explaining the study to the samples and obtaining written informed consent from them. The researcher made herself obliged to adhere to the ethical issues in the Declaration of Helsinki. The participants were assured that participating in the study is voluntary and they can be excluded from the study at any stage of the research as they wish. Besides, the necessary permits were issued by the hospital authorities to carry out the research.

The SPSS software ver.16 (SPSS Inc., Chicago, IL, USA) was used for data analysis. The P-value of less than 0.05 was considered statistically significant. The independent T-test, Fisher's exact test, and chi-square test were used to compare the individual characteristics of groups. Following examining the data related to the FAD questionnaire, the functioning score was normally distributed. Therefore, the repeated measures analysis of variance (RM-ANOVA) was used to evaluate the effect of the intervention on the families' functioning, in three stages of study.

\section{RESULTS}

In this study, the mean age and standard deviation of the studied subjects were $41.84 \pm 10.14$ years; most of them were female (57.8\%), married (75\%), often had an academic education (37.5\%), the mean number of hospitalizations of the schizophrenic patients was $4.96 \pm 3.10$ days, and the mean score of total family functioning of caregivers were $163.91 \pm 13.61$.

According to the data, there was no significant difference concerning the demographic information between the intervention and control groups $(\mathrm{P}>0.05)$ (Table 2). In addition, the groups were comparable in terms of dimensions and the total family functioning score in the pre-intervention phase $(\mathrm{P}>0.05)$. In the post-intervention phase, the problems-solving subscale score was significantly lower in the intervention group $(11.80 \pm 2.13)$ than in the control group $(15.53 \pm 2.87)$ $(\mathrm{P}=0.012)$. In the 2 weeks after intervention phase, a significant difference was found between the mean score of intervention and control groups in terms of dimensions of role (21.71 versus 23.43, $\mathrm{P}=0.015)$, affective involvement (19.03 versus $21.59, \mathrm{P}=0.017$ ), behavior control (23.90 versus 26.93, $\mathrm{P}=0.045$ ), general functioning (27.15 versus 31.40 , $\mathrm{P}=0.013$ ), and total family functioning (134.12 versus $153.09, \mathrm{P}=0.001$ ), so that the intervention group score was lower than the control group (Table 3).

The RM-ANOVA test showed a significant difference between the two groups in terms of the all dimensions of family functioning and total family functioning score during the three study stages $(\mathrm{P}<0.05)$ (Table 3). In addition, the RM-ANOVA test showed that the time factor was effective in decreasing the score of the dimensions of affective responsiveness $(\mathrm{F}=21.539, \mathrm{P}=0.0001)$, general functioning $(\mathrm{F}=39.622$, $\mathrm{P}=0.0001)$, and total family functioning $(\mathrm{F}=13.906, \mathrm{P}=0.0001)$ in the intervention group $(\mathrm{P}<0.05)$ (Table 3$)$.

Figure 2 also shows the downward trend of total family functioning in the intervention group compared to the control group over time (during the three study phases).

\section{DISCUSSION}

The results show, the two groups were comparable in terms of individual characteristics and in terms of dimensions and the total family

Table 2. Demographic variables of family caregivers

\begin{tabular}{lrrr}
\multicolumn{1}{c}{ Characteristic } & \multicolumn{2}{c}{ Group } & \\
\cline { 2 - 3 } & $\begin{array}{c}\text { Intervention } \\
(\mathrm{N}=32)\end{array}$ & $\begin{array}{c}\text { Control } \\
(\mathrm{N}=32)\end{array}$ & \\
\hline Gender & $14(43.8)$ & $13(59.4)$ & \\
$\quad$ Male & $18(56.2)$ & $19(59.4)$ & \\
$\quad$ Female & & & 1 \\
Marital status & $8(25.0)$ & $8(25.0)$ & \\
$\quad$ Single & $24(75.0)$ & $24(75.0)$ & \\
$\quad$ Married & $9(28.1)$ & $11(34.4)$ & \\
Level of education & $10(31.3)$ & $10(31.3)$ & \\
$\quad$ Under diploma & $13(40.6)$ & $11(34.4)$ & \\
$\quad$ High school & $41.34 \pm 1.80$ & $42.34 \pm 9.96$ & 0.71 \\
$\quad$ University & $4.77 \pm 2.82$ & $5.15 \pm 3.38$ & 0.62 \\
Age (y) & & \\
No. of hospitalizations of patients & & \\
\hline
\end{tabular}

Values are presented as number (\%) or mean \pm standard deviation, unless otherwise stated. 
Table 3. Mean score of within and between group of dimensions of functioning in intervention and control group at three stages of study

\begin{tabular}{|c|c|c|c|c|c|c|c|}
\hline \multirow{3}{*}{$\begin{array}{l}\text { Dimensions of } \\
\text { functioning }\end{array}$} & \multicolumn{3}{|c|}{ Time } & \multicolumn{4}{|c|}{ RM ANOVA } \\
\hline & \multirow{2}{*}{ Pre-intervention } & \multirow{2}{*}{ Post-intervention } & \multirow{2}{*}{$\begin{array}{l}2 \text { Weeks after } \\
\text { intervention }\end{array}$} & \multicolumn{2}{|c|}{ Time* } & \multicolumn{2}{|c|}{ Group $\times$ time $^{\dagger}$} \\
\hline & & & & $\mathrm{F}$ & P-value & $\mathrm{F}$ & P-value \\
\hline Problem solving & & & & & & 34.127 & 0.0001 \\
\hline Intervention & $17.00 \pm 2.30$ & $11.80 \pm 2.13$ & $11.95 \pm 2.49$ & 22.01 & 0.0001 & & \\
\hline Control & $14.36 \pm 2.04$ & $15.53 \pm 2.87$ & $14.31 \pm 1.71$ & 50.99 & 0.001 & & \\
\hline \multicolumn{8}{|l|}{ T-test } \\
\hline T-value & 4.846 & -5.88 & -4.39 & & & & \\
\hline P-value & 0.474 & 0.012 & 0.716 & & & & \\
\hline Communication & & & & & & 9.554 & 0.0001 \\
\hline Intervention & $18.01 \pm 2.18$ & $15.97 \pm 2.45$ & $15.49 \pm 2.96$ & 3.024 & 0.05 & & \\
\hline Control & $16.01 \pm 1.56$ & $17.28 \pm 2.17$ & $16.50 \pm 1.86$ & 7.72 & 0.001 & & \\
\hline \multicolumn{8}{|l|}{ T-test } \\
\hline T-value & 4.217 & -2.243 & -1.62 & & & & \\
\hline P-value & 0.162 & 0.385 & 0.168 & & & & \\
\hline Roles & & & & & & 8.202 & 0.001 \\
\hline Intervention & $25.08 \pm 2.08$ & $21.34 \pm 1.95$ & $21.71 \pm 3.42$ & 22.400 & 0.0001 & & \\
\hline Control & $23.86 \pm 1.83$ & $22.59 \pm 1.75$ & $23.43 \pm 1.98$ & 18.79 & 0.0001 & & \\
\hline \multicolumn{8}{|l|}{ T-test } \\
\hline T-value & 2.488 & -2.685 & -2.46 & & & & \\
\hline P-value & 0.732 & 0.573 & 0.015 & & & & \\
\hline Affective responsiveness & & & & & & 30.307 & 0.0001 \\
\hline Intervention & $20.98 \pm 1.53$ & $16.71 \pm 2.61$ & $15.67 \pm 2.66$ & 21.539 & 0.0001 & & \\
\hline Control & $18.68 \pm 1.73$ & $19.53 \pm 2.85$ & $18.90 \pm 2.17$ & 47.97 & 0.0001 & & \\
\hline \multicolumn{8}{|l|}{ T-test } \\
\hline T-value & 5.626 & -4.110 & -5.30 & & & & \\
\hline P-value & 0.375 & 0.738 & 0.260 & & & & \\
\hline Affective involvement & & & & & & 7.208 & 0.001 \\
\hline Intervention & $22.72 \pm 2.44$ & $20.28 \pm 2.81$ & $19.03 \pm 3.22$ & 12.988 & 0.0001 & & \\
\hline Control & $22.00 \pm 1.98$ & $20.93 \pm 2.48$ & $21.59 \pm 1.98$ & 13.29 & 0.0001 & & \\
\hline \multicolumn{8}{|l|}{ T-test } \\
\hline T-value & 1.302 & -0.987 & -3.82 & & & & \\
\hline $\mathrm{P}$-value & 0.348 & 0.655 & 0.017 & & & & \\
\hline Behavior control & & & & & & 28.441 & 0.0001 \\
\hline Intervention & $29.10 \pm 3.21$ & $22.50 \pm 2.93$ & $23.90 \pm 3.58$ & 16.991 & 0.0001 & & \\
\hline Control & $26.19 \pm 2.27$ & $27.06 \pm 3.97$ & $26.93 \pm 2.67$ & 39.00 & 0.0001 & & \\
\hline \multicolumn{8}{|l|}{ T-test } \\
\hline T-value & 4.173 & -5.217 & -4.86 & & & & \\
\hline P-value & 0.197 & 0.170 & 0.045 & & & & \\
\hline General functioning & & & & & & 16.791 & 0.0001 \\
\hline Intervention & $38.76 \pm 3.56$ & $28.88 \pm 4.68$ & $27.15 \pm 5.15$ & 39.622 & 0.0001 & & \\
\hline Control & $35.02 \pm 7.17$ & $34.53 \pm 4.64$ & $31.40 \pm 3.94$ & 61.62 & 0.0001 & & \\
\hline \multicolumn{8}{|l|}{ T-test } \\
\hline T-value & 2.640 & -4.842 & -3.70 & & & & \\
\hline P-value & 0.363 & 0.741 & 0.013 & & & & \\
\hline Total family functioning & & & & & & 33.680 & 0.0001 \\
\hline Intervention & $171.68 \pm 10.13$ & $137.51 \pm 14.08$ & $134.12 \pm 19.37$ & 13.906 & 0.0001 & & \\
\hline Control & $156.15 \pm 12.23$ & $157.46 \pm 16.47$ & $153.09 \pm 9.90$ & 57.26 & 0.0001 & & \\
\hline \multicolumn{8}{|l|}{ T-test } \\
\hline T-value & 5.53 & -5.20 & -4.93 & & & & \\
\hline P-value & 0.441 & 0.810 & 0.001 & & & & \\
\hline
\end{tabular}

Values are presented as mean \pm standard deviation, unless otherwise stated.

*Time effect on variables. 'The interactive effect of time and group on variables.

functioning score. This increases the reliability of the findings. In this study, mean score of total family functioning of all caregivers was equal to $163.91 \pm 13.61$ that indicate family dysfunction. In line with this finding, Foruzandeh et al. ${ }^{23)}$ demonstrated that functioning in families with schizophrenia patient is more impaired than in the case of mood disorders in all dimensions, especially in the roles, affective involve- 


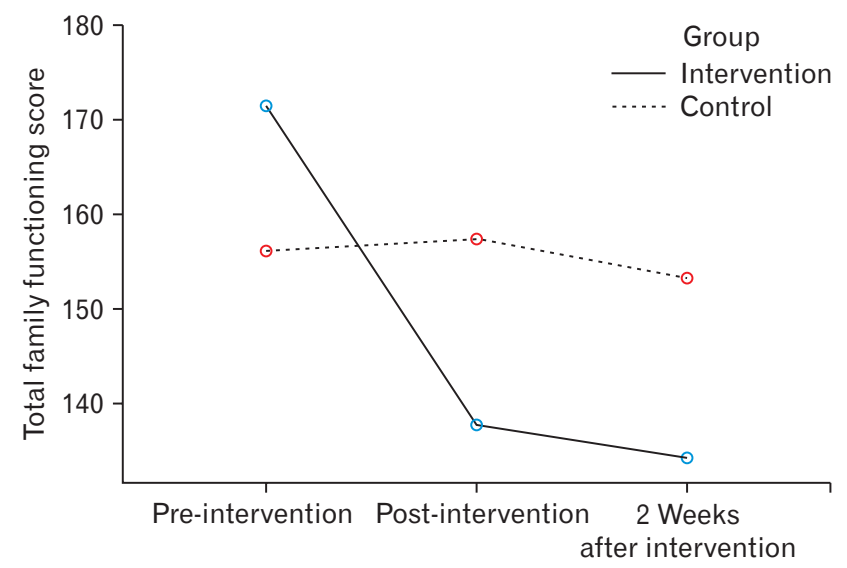

Figure 2. The comparison of total family functioning score of the two groups of intervention (peer-assisted education) and control, in three stages (pre-intervention, post-intervention, 2 weeks after intervention) of the study, based on repeated measures analysis of variance test result.

ment, and general functioning dimensions. Studies were showed that family caregivers of schizophrenia patients suffer from family dysfunction due to stigma, ${ }^{24)}$ social isolation that increased psychological burden, not knowing the nature of the disease, economic and social problems, and consequently significant harm to family adjustment and functioning. ${ }^{25,26)}$

Other findings of this study revealed in the post-intervention phase, problem-solving dimension was better in the intervention group than the control group. Also, 2 weeks after intervention, the mean score of total functioning, roles, affective involvement, behavior control, and general functioning dimensions in the intervention group were better than the control group $(\mathrm{P}<0.05)$. Indeed, with the time passes, practicing and engaging more with what was taught, will enhance learning and change the behavior. ${ }^{27)}$ In this regard Chien et al., ${ }^{28)}$ in a study in 2018, showed that the 9-month peer-led family support group program for 101 Chinese families of people with recent-onset psychosis in Hong Kong can significantly improve the family functioning and perceived burden, in addition to improving the patients' mental state, readmission rates and functioning during 48 months of follow-up. Chien and Thompson ${ }^{29)}$ in other study reported that 2-hour group sessions ( $n=14$ ) of peer support group intervention compared to psycho-education group and standard psychiatric care improved family functioning of people with schizophrenia $(\mathrm{P}<0.005, \mathrm{P}<0.001)$ and reduced readmission their patients $(\mathrm{P}<0.01)$. Studies that measure the impact of peer intervention on all dimensions of family functioning of schizophrenia patient not found. However, Oksuz et al. ${ }^{30)}$ examined the effect of psychoeducation on the expressed emotion and family functioning of the first-episode schizophrenia. Finally, significant differences were reported in the scores of all dimensions of family functioning in the experimental group compared to the control group. ${ }^{30)}$ Also in study of Azizi Fahliani et al. ${ }^{31)}$ entitled as "The effect of social work intervention on family function in schizophrenia patients", found a significant difference in all dimensions of family functioning in the two groups and suggested that education about the disease and adaptation skills is needed for family competence and abilities.

According to recently studies, peer-assisted education is likely to increase caregiver functioning by enhancing the knowledge, skills, providing better control of relationships between family members, and creating social support for disease management results. In addition, same feeling and shared belief among family caregivers and peer person induces a strong sense of coherence and effectiveness of social learning. ${ }^{18)}$

Peer-assisted education is a supportive, flexible and interactive mode ${ }^{18)}$ and can be considered as a community-based intervention in populations with limited resources, staff shortages and lack of access to professional-led group intervention for patient caregivers. ${ }^{28)}$ The results of this study can be added to previous evidence on the effects of the peer-assisted education method. It is suggested to pay more attention to the families of these patients and use the results of this study to educate the family caregivers of schizophrenia patients and other psychiatric patients.

One of the limitations of the present study was the limited time of the researcher to carry out the project, which resulted in the short training course. Also, the individual differences and the psychological state of the studied subjects while answering the questions that could influence how they answer the questions were the issues that could not be controlled by the researcher.

\section{CONFLICT OF INTEREST}

No potential conflict of interest relevant to this article was reported.

\section{FUNDING}

The research was funded by Army (Aja) University of Medical Sciences.

\section{ACKNOWLEDGMENTS}

This study was supported by the Army (Aja) University of Medical Sciences. We would like to thank the clinical psychologist, Zohreh Manoochehri for providing scientific advice on the caregivers' training, and all the people who participated in the study.

\section{ORCID}

Nahid Rajai: https://orcid.org/0000-0002-5671-6855

Behnaz Lami: https://orcid.org/0000-0003-3604-2416

Amir Hosein Pishgooie: https://orcid.org/0000-0001-8042-2657

Hengameh Habibi: https://orcid.org/0000-0003-3811-8402

Fatemeh Alavizerang: https://orcid.org/0000-0003-3580-4087 


\section{REFERENCES}

1. Yu Y, Liu ZW, Zhou W, Chen XC, Zhang XY, Hu M, et al. Assessment of burden among family caregivers of schizophrenia: psychometric testing for Short-Form Zarit Burden Interviews. Front Psychol 2018;9: 2539.

2. Navidian A, Kermansaravi F, Rigi SN. The effectiveness of a group psycho-educational program on family caregiver burden of patients with mental disorders. BMC Res Notes 2012;5:399.

3. Tamizi Z, Fallahi-Khoshknab M, Dalvandi A, Mohammadi-Shahboulaghi F, Mohammadi E, Bakhshi E. Defining the concept of family caregiver burden in patients with schizophrenia: a systematic review protocol. Syst Rev 2019;8:289.

4. Ribe JM, Salamero M, Perez-Testor C, Mercadal J, Aguilera C, Cleris M. Quality of life in family caregivers of schizophrenia patients in Spain: caregiver characteristics, caregiving burden, family functioning, and social and professional support. Int J Psychiatry Clin Pract 2018;22:2533.

5. Sawant NS, Jethwani KS. Understanding family functioning and social support in unremitting schizophrenia: a study in India. Indian J Psychiatry 2010;52:145-9.

6. Kushan M, Vaghei S. Psychiatric nursing: mental health 2. Tehran: Andisheh Rafi; 2015.

7. Sharif F, Mahmoudi A, Shooshtari AA, Vossoughi M. The effect of family-centered psycho-education on mental health and quality of life of families of adolescents with bipolar mood disorder: a randomized controlled clinical trial. Int J Community Based Nurs Midwifery 2016;4:229-38.

8. Shamsaei F, Cheraghi F, Bashirian S. Burden on family caregivers caring for patients with schizophrenia. Iran J Psychiatry 2015;10:239-45.

9. McFarlane WR. Family interventions for schizophrenia and the psychoses: a review. Fam Process 2016;55:460-82.

10. Yazici E, Karabulut U, Yildiz M, Baskan Tekes S, Inan E, Cakir U, et al. Burden on caregivers of patients with schizophrenia and related factors. Noro Psikiyatr Ars 2016;53:96-101.

11. Caqueo-Urizar A, Alessandrini M, Urzua A, Zendjidjian X, Boyer L, Williams DR. Caregiver's quality of life and its positive impact on symptomatology and quality of life of patients with schizophrenia. Health Qual Life Outcomes 2017;15:76.

12. Hashemian P, Edris Sedaghati M. Comparison of family functioning between patients with schizophrenia and patients with Bipolar I disorder. J North Khorasan Univ Med Sci 2015;7:929-37.

13. Epstein NB, Baldwin LM, Bishop DS. The McMaster Family Assessment Device. J Marital Fam Ther 1983;9:171-80.

14. Wan KF, Wong MMC. Stress and burden faced by family caregivers of people with schizophrenia and early psychosis in Hong Kong. Intern Med J 2019;49 Suppl 1:9-15.

15. Nadem Buoeni M, Ramzani T, Haghduost A. Survey knowledge of caregivers of patients of schizophrenia about home care in. J Holist Nurs Midwifery 2008;18:43-50.

16. Kheirabadi GR, Rafizadeh M, Omranifard V, Yari A, Maracy MR, Meh- rabi T, et al. Effects of needs-assessment-based psycho-education of schizophrenic patients' families on the severity of symptoms and relapse rate of patients. Iran J Nurs Midwifery Res 2014;19:558-63.

17. Cook JA, Heller T, Pickett-Schenk SA. The effect of support group participation on caregiver burden among parents of adult offspring with severe mental illness. Fam Relat 1999;48:405-10.

18. Chien WT, Norman I. The effectiveness and active ingredients of mutual support groups for family caregivers of people with psychotic disorders: a literature review. Int J Nurs Stud 2009;46:1604-23.

19. Farsi Z, Eslami R, Sajadi A, Afaghi E. Comparing the effect of peer education and orientation tour on the hemodynamic indices of patients candidate for coronary angiography. Med Surg Nurs J 2016;4:65-72.

20. Najafi L, Moghaddam Tabrizi F, Ebrahimi M. The effect of peer-based support on health-promoting behaviors in breast cancer survivors in academi hospitals and research centers in Urmia in 2015-16. Nurs Midwifery J 2018;15:795-805.

21. Masoudnia E. The relationship between deficiency of family cohesion and prevalence of physical and mental fatigue among Yazd province police families. J Mil Med 2017;19:306-14.

22. Yoosefi N. An investigation of the psychometric properties of the McMaster Clinical Rating Scale (MCRS). Train Meas 2012;3:83-112.

23. Foruzandeh N, Parvin N, Deris F. Family functioning in families of patients with schizophrenia and mood disorders. Chronic Dis J 2015;3:21-6.

24. Taghva A, Farsi Z, Javanmard Y, Atashi A, Hajebi A, Khademi M. Stigma barriers of mental health in Iran: a qualitative study by stakeholders of mental health. Iran J Psychiatry 2017;12:163-71.

25. Fitryasari R, Yusuf A, Nursalam, Tristiana RD, Nihayati HE. Family members' perspective of family resilience's risk factors in taking care of schizophrenia patients. Int J Nurs Sci 2018;5:255-61.

26. Karamlou S, Mottaghipour Y, Borjali A, Sadeghi MS, Khanipour H. Effective factors in experiencing shame in families of patients with severe psychiatric disorders: perceived stigma, rejection sensitivity, cognitive appraisal. Clin Psychol Stud 2016;6:25-39.

27. Hong EJ, Kim HY. The impact of simulation-based learning in undergraduate courses on the problem solving and clinical competence for new nurses. J Korea Contents Assoc 2016;16:617-26.

28. Chien WT, Bressington D, Chan SW. A randomized controlled trial on mutual support group intervention for families of people with recentonset psychosis: a four-year follow-up. Front Psychiatry 2018;9:710.

29. Chien WT, Thompson DR. An RCT with three-year follow-up of peer support groups for Chinese families of persons with schizophrenia. Psychiatr Serv 2013;64:997-1005.

30. Oksuz E, Karaca S, Ozaltın G, Ates MA. The effects of psychoeducation on the expressed emotion and family functioning of the family members in first-episode schizophrenia. Community Ment Health J 2017;53:464-73.

31. Azizi Fahliani M, Masafi S, Khankeh HR, Raheb G, Rezaei O. The effect of social work interventions on family function improvement in schizophrenic patients. Int Res J Biol Sci 2015;4:1-6. 